Luiz Antonio Luzio Coelho [PUC/Rio]

\title{
Mudando de patamar: a pesquisa no design
}

\author{
Changing the pattern: research in design
}

\begin{abstract}
pesquisa, ensino de design, metodologia
Baseando-se no contexto histórico do ensino do Design em nosso país a partir da criação da primeira pósgraduação stricto sensu brasileira, o autor-na condição de coordenador de pesquisa do Departamento de Artes \& Design da PUC-Rio—traz o relato de sua experiência com grupos de pesquisa e orientação de bolsistas de iniciação científica por mais de dez anos. Descreve esse percurso pautando as diversas fases percorridas com exemplos concretos dos resultados. O registro do processo representa a intenção de poder contribuir para a discussão do desenvolvimento da investigação científica do Design no Brasil.
\end{abstract}

research, design teaching, methodology

As Research Coordinator of the Department of Arts \& Design at Pontifical Catholic Universty of Rio de janeiro, the author brings in his own experience of more than ten years as leader of research groups made up with both undergraduate and graduate students. The historical context of Design teaching from the creation of the first formal post-graduate program of Design in Brazil is used as the backdrop for this discussion. This presentation aims at showing the process of such history thereby collaborating for a better understanding of Design scientific investigation in this country.

\section{O que é a pesquisa?}

A pergunta acima é freqüentemente formulada na academia. Quais seriam os limites daquilo que se aceita como pesquisa e o que se percebe como não pesquisa? Um levantamento de dados ou uma busca de fontes seriam pesquisa? Embora, semanticamente, a palavra pesquisa pressuponha a idéia de busca, quando se fala em pesquisa ou investigação científica, se está falando, na realidade, de uma busca qualificada. Assim, um simples levantamento não poderia ser tomado como pesquisa nesta acepção. A idéia de averiguação e sistematização de dados, com a finalidade de se "... descobrir ou estabelecer fatos ou princípios relativos a um campo qualquer do conhecimento" está implícita na pesquisa acadêmica.1 Isto quer dizer que a pesquisa acadêmica não prescinde da análise e interpretação dos dados. A sistematização, por sua vez, implica identificar campos de trabalho e caracterizá-los como temas através dos dados ou aspectos que se observa e que se pretende tratar durante a investigação.

Identificado o campo, tema e dados, costuma-se definir objetivos, relevância e metodologia. A clareza na caracterização da pesquisa nesta primeira fase torna-se essencial para a compreensão do que é o trabalho, tanto para o pesquisador quanto para terceiros. A tarefa de identificação e classificação (mapeamento) de dados continua em todo o processo investigatório e o pesquisador tem de estar preparado para novos dados que venham a surgir e se tornar relevantes, mesmo que não tinham sido previstos de antemão. Isto pode alterar a própria caracterização da pesquisa e o investigador deve ter a paciência para reformulá-la. O limite da reformulação, na realidade, é o tempo e disponibilidade de recursos que se tem. Muitas vezes, prazos e recursos materiais - financeiros ou de infra-estrutura, como, por exemplo, limite de acesso a equipamentos - pode dificultar ou mesmo impedir reformulações. Em tais circunstâncias, é preciso registrar o ocorrido no relatório da pesquisa. Em geral, se este for o caso, encerra-se a pesquisa em sua feição original - com respectivos achados e conclusões - para só então delinearse nova pesquisa com o

perfil reformulado.

A noção de cientificidade de uma investigação está no rigor com que se procede, da fase conceitual (caracterização da pesquisa) à análise e interpretação. As fontes e variáveis são 
sempre pré-identificadas e classificadas. A qualidade tratamento que se dá a estas é garantida por uma metodologia adequada. Os métodos aplicados precisam revestir-se de objetividade e clareza; serão estes os mais simples e econômicos possíveis. Somente após a aplicação da metodologia estabelecida, que pressupõe reflexão teórica e experimentação, é que se pode falar em análise e de resultados. Este é o momento final da pesquisa, quando se apresenta o que foi descoberto: quais os fatos ou princípios achados em relação ao campo do conhecimento; que contribuição trouxe para a teoria, ciência, prática profissional ou relações sociais; quais são suas aplicações, seus desdobramentos, a prospecção dos resultados.

\section{Pesquisa em Design}

Grande desafio para os cursos de Design no Brasil, sobretudo antes da criação da primeira pósgraduação, em 1994, a pesquisa em Design ganha vulto em nosso país e hoje conta com a massa crítica de quatro mestrados e um doutorado. Não queremos inferir aqui que antes da pósgraduação stricto sensu não havia pesquisa em Design no Brasil. ${ }^{2} \mathrm{O}$ desafio a que nos referimos diz respeito à dificuldade no reconhecimento do foro científico de nossos trabalhos por parte de nossos pares de outras áreas. Havia mesmo um preconceito nas próprias IES em relação ao que a pesquisa em Design teria de científico. De certa forma tínhamos certa culpa quando insistíamos no aforismo "Design se faz fazendo". Se refletirmos melhor sobre a máxima, verificaremos que na medida em que aquilo que no Design se faz realmente a partir da prática, ocorre virtualmente em todos os campos de atividade. Não é prerrogativa, portanto, desta ou daquela área.

De qualquer maneira, tivemos de enfrentar esse preconceito interno, associado ao não entendimento quanto à nossa inserção acadêmica nas agências de fomento: ora pertencemos às Engenharias, ora à Arquitetura e Urbanismo. A reafirmação da interdisciplinaridade do Design, talvez uma falácia na extensão dessa afirmação (já que também todas as áreas têm diferentes graus de interdisciplinaridade), parece contribuir para a idéia de que Design caberia em qualquer e todo lugar.

Vizinho sim das Artes, Engenharias, Comunicação Social e da Arquitetura, por exemplo, o Design, contudo, desenvolveu sua própria práxis e elaborou seu corpo teórico a partir de reflexões anteriores. Passou a gerar conceitos próprios e práticas que lhe peculiarizam. O que se faz em termos de Design participativo, o que se examina na área do chamado Design vernacular, a preocupação que se tem com legibilidade, a consideração com aspectos afetivos do objeto, o olhar, enfim, do designer é único e, podemos afirmar, tem sua especificidade.

No momento da criação do mestrado da PUC-Rio, em 1994, houve sugestões e certa pressão para que criássemos um curso profissionalizante ou "pelo menos no início para ver como ficaria" e, por nossa insistência, e exatamente em razão do preconceito do "cunho prático" do Design, não transigimos. Foi criada a pós stricto sensu. ${ }^{3}$

A partir desse ponto, as evidências têm sido cabais e a produção científica de docentes e pósgraduandos dos programas stricto e lato sensu do país, através das monografias de fim de curso, artigos nas revistas científicas ou participação de pesquisadores em congressos não apenas de Design, mas de áreas mais tradicionais, com bons trabalhos de natureza teórica, atestam que vivemos outro paradigma.

\section{Condicionadores da pesquisa}

Pesquisas ocorrem tanto na pós quanto na graduação, apesar de associarmos pesquisa a trabalhos de mestrado e doutorado. Lembramos que as bolsas de iniciação científica, oferecidas pelas agências de fomento e pelas próprias IES, traduzem o desejo dos centros de decisão em fomentar a pesquisa no âmbito da graduação.

Grande parte dos currículos de Design em nível de graduação tem como balizador do progresso do aluno os projetos de realização, que compreendem a concepção, planejamento e prototipagem de objetos. Estes projetos, muitas das vezes, privilegiam a finalização do produto em detrimento da concepção e planejamento. Raramente vão além da produção do objeto em si para aspectos de recepção e desuso, por exemplo. No que se refere à criação e planejamento, o

\footnotetext{
${ }^{2}$ Em realidade, as bolsas PIBIC já eram concedidas ao Design antes da criação do mestrado da PUC em 1994.0 nívelcientífico destes trabalhos, todavia, melhorou sensivelmente após o mestrado. Hoje bolsistas PIBIC e pósgraduandosdividem os mesmos espaços de pesquisa.
} 

${ }^{3}$ Coelho, Luiz Antonio L. (1995). Ensino do design: Como nos vemos, como nos vêem. Pesquisa e pós-graduação
emdesign no Brasil: óbices e possíveis caminhos. Anais do $5^{\circ}$ Encontro Brasileiro das Escolas de Design. Rio de
Janeiro:Faculdade Carioca, 1995.

chamado método projetual costuma fornecer ao aluno, sem muita discussão, as etapas que deverão ser cumpridas na execução do trabalho. É o caso, por exemplo, das fases de levantamento de dados, geração de alternativas, partido adotado, experimentação, etc. Tal atitude resulta na adoção de uma fórmula que o aluno tende a aplicar em qualquer projeto, com qualquer objeto ao longo do curso. Em nossa opinião, a hegemonia do método projetual no currículo da graduação em Design, bem como a tendência deste ser adotado irrestritamente, deixando de incorporar, por exemplo, aspectos históricos, filosóficos e semióticos no ato da projetação, obscurece o potencial do trabalho científico. Não queremos afirmar que todos os projetos deixam de lado esses aspectos. Afirmamos, isto sim, que o método privilegia o produto final, o ato de produção. Trata-se de uma lacuna em relação aos requisitos da pesquisa acadêmica.

\section{Estratégias de integração}

A integração entre graduação e pós-graduação não apenas é recomendada, mas dela depende o nível das pesquisas, uma vez que pesquisadores principiantes têm a oportunidade de atingir excelência com maior rapidez. Quanto mais cedo o aluno da graduação, com potencial para o trabalho investigatório-científico, tiver contato com grupos mais maduros de pesquisa maior o rendimento do trabalho e melhor o nível dos resultados obtidos. A troca entre pesquisadores iniciantes e veteranos torna-se, assim, uma pedra de toque para o sucesso do trabalho desenvolvido no âmbito dos projetos de pesquisa. Bolsas IC e disciplinas de introdução à pesquisa tornam-se fatores importantes dessa integração.

A associação intra e inter-institucional também são recomendadas, assim como a cooperação entre pesquisadores nacionais e estrangeiros. Há hoje no Brasil, patrocinados pela CAPES, programas de redes de pesquisa com grande número de países e de IES renomadas na área do Design. Lançar mão dessa integração ajuda na obtenção de melhores resultados também.

Igualmente, o incentivo à participação de associações científicas, como a SBDI, e de seus encontros periódicos, resulta em potencial para redes inter-universitárias e um caminho para a formação de grupos de pesquisa de excelência internacional. Os esforços dessas associações, que mantêm relações com acadêmicos de outros países e promovem a ponte entre estes e pesquisadores brasileiros, ajudam na mudança do patamar da pesquisa em Design.

É natural que se pense hoje na pesquisa em termos globais. Especificamente em termos de Design informacional, é preciso pensar em profissionais (designers) para uma clientela internacional. Isso passa pelo equacionamento da alfabetização informacional e cultural, que, por sua vez, mexe com identificação dos processos de utilização de tipos com legibilidade internacional e ícones reconhecidos internacionalmente. Este é um campo que se abre para nossos pesquisadores do Design. A preocupação em cobrir deficiências dessa ordemanalfabetismo cultural e informacional e promover a Educação Transnacional—não é apenas nossa. A Internacional Association of University Presidents/IAUP, e a Organisation for Economic Co-operation and Development/OECD trabalham na internacionalização dos currículos e vislumbram aspectos que dizem respeito ao Design informacional. ${ }^{4}$

\section{NEL: Núcleo de Estudos do Design do Livro}

Temos trabalhado com um grupo de pesquisa que incorpora alunos de graduação voluntários e bolsistas PIBIC. Em sua grande maioria, os membros deste núcleo são alunos de pósgraduação - mestrandos e doutorandos - mestres e doutores.

O Núcleo de Estudos do Design do Livro foi criado em 2003 com a finalidade de desenvolver pesquisas sobre a visualidade do livro. O NEL conta hoje com uma equipe de dezenove investigadores, dos quais três doutores, dois doutorandos da PUC e um doutorando da UFF; três mestres e seis mestrandos dois graduandos PIBIC e duas voluntárias da graduação. $O$ grupo reúne-se a cada quinze dias, ocasião em que seus membros apresentam o resultado de suas pesquisas específicas relativas ao tema livro, sob a forma de seminário. Os resultados em 2004 e primeiro semestre de 2005 foram:

- um simpósio interno, Caminhos do livro, em 9 de março de 2004, sobre as perspectivas de utilização do códice; 


\section{Infodesıgn}

${ }^{4}$ Ver OECD, Education at a Glance 2003, Table C3.3; IDP Education Australia, 'Curriculum Development for Internationalisation', OECD/CERI Study, March 1995, p20; e Betty Leask, 'Bridging the Gap-Internationalising University Curricula' , Journal of Studies in International Education, Vo15, No 2, Summer 2001, pp 100-115.

- um projeto homônimo com pesquisa para um curso a distância, ora em execução, a ser veiculado pela Coordenação Central de Ensino a Distância da PUC-Rio/CCEAD;

- um livro com o material gerado das apresentações dos seminários (o livro está pronto e em fase de contato com editora) previsto para ser lançado em setembro de 2005, provavelmente por ocasião do simpósio Roger Chartier: apropriações de um pensamento no Brasil, organizado pela PUC-Rio e UFRJ;

- um simpósio interno intitulado Fronteiras do livro, realizado fora do Rio de Janeiro de 21 a 23 de abril de 2005, para iniciar nova fase de pesquisa, com planejamento para a segundo semestre de 2005 e primeiro de 2006; e

- o evento PUC por um dia, constante de cinco oficinas sobre a produção de livros para alunos do ensino básico.

Os resultados esperados para o ano de 2006 são:

- um curso a distância Caminhos do Livro, em execução;

- um segundo livro está previsto, a partir da expertise dos pesquisadores envolvidos, cujos capítulos, de autoria dos pesquisadores mestres e doutores, discutirão a questão da leitura, considerando não somente o suporte livro, mas os que contemplam o hipertexto, além daqueles baseados em textos e imagens, como filmes e jogos eletrônicos, que utilizam CDs, aparelhos de vídeo, celulares e outras máquinas emergentes que, sem dúvida, farão parte do grande concerto de mídias à disposição dos futuros espaços de acesso à informação e ao conhecimento.

As dissertações produzidas no âmbito do NEL e já defendidas foram:

- Julie de Araújo PIRES. A reconstrução do livro: um estudo em design acerca das possibilidades do livro a partir da hipertextualidade eletrônica.

- Renata Vilanova LIMA. Vi Lobato, através de Emília-Emílias ilustradas para três fases de Lobato.

- Ana Sofia MARIZ. Editora Civilização Brasileira: o design gráfico de um projeto editorial (1959-1970).

As orientações relacionadas ao tema em andamento são:

Mestrado:

- Pedro Vicente F. VASCONCELOS. O Design dos quadrinhos. Início: 2004.

- Daniel Moreira de Souza PINNA. A construção de personagem na animação. Início: 2004.

- Eduardo Andrade de OLIVEIRA. A formação da personagem na narrativa com utilização de bonecos. Início: 2005.

- Guilherme XAVIER. Narrativas em jogos eletrônicos. Início: 2005.

Teses:

- Eliane Bettocchi GODINHO. Incorporais RPG - socialização interativa e narrativa hipermidiática. Início: 2004

- Suzana Valladares FONSECA. O problema da forma/função no discurso do Design gráfico. Início: 2003.

Iniciação Científica:

- Rodrigo do Carmo NEVES. Grupo de Estudos do Design do Livro. PIBIC. Período: agosto de 2004 - julho de 2005.

- Roberta Venâncio MARTINS. Grupo de Estudos do Design do Livro. PIBIC. Período: agosto de 2004 - julho de 2005. 


\section{Sobre o autor}

Luiz Antonio Coelho é doutor em Comunicação Social pela Universidade de Nova York, e pós doutor pela Universidade de Reading [Inglaterra]. Desde 1986, é professor associado do Departamento de Artes e Design da PUC do Rio de Janeiro, onde é membro da Comissão de Pósgraduação. É autor de diversos artigos publicados em periódicos nacionais e internacionais, e de capítulos de livros nas áreas de design e comunicação social. 